\title{
Metabolic Bone Disease in Premature Neonates: An Unmet Challenge
}

\author{
(1) Swathi Chacham ${ }^{1}$, (1) Rachna Pasi2, (1) Madhuradhar Chegondi3 , (1) Najeeb Ahmad ${ }^{1}$, (1) Shanti Bhusan Mohanty \\ ${ }^{1}$ All India Institute of Institute of Medical Sciences, Rishikesh, India \\ ${ }^{2}$ Himalayan Institute of Medical Sciences, Dehradun, India \\ 3 University of lowa, Carver College of Medicine, lowa City, USA
}

\begin{abstract}
Metabolic bone disease (MBD) is an important cause of morbidity in premature, very low birth weight (VLBW) and sick infants and, if left undiagnosed, may lead to structural deformities and spontaneous fractures. MBD is defined as impaired bone mineralization in a neonate with lower than expected bone mineral levels in either a fetus or a neonate of comparable gestational age and/or weight, coupled with biochemical abnormalities with or without accompanying radiological manifestations. MBD has been reported to occur in $16 \%$ to $40 \%$ of extremely low birth weight neonates and presents by 6-16 weeks after birth. Insufficient calcium and phosphorous stores during the phase of accelerated growth predispose to MBD in neonates along with the use of some medications such as caffeine or steroids, prolonged parenteral nutrition and chronic immobilization. Enhanced physical activity in preterm infants facilitates bone mineralization and weight gain. Biochemical abnormalities tend to worsen significantly, as the severity of disease progresses. These abnormalities may include hypocalcemia, hypophosphatemia, hyperphosphatasia and secondary hyperparathyroidism. In addition, urinary phosphate wasting and hypovitaminosis D can be additional complications. Conversely, biochemical abnormalities may not be accompanied by rachitic changes. Newer diagnostic modalities include non-invasive bone densitometry by quantitative ultrasound over the mid-tibial shaft. The management of MBD includes adequate calcium, phosphorous and vitamin D supplementation, along with optimum nutrition and physical activity. Similarly, preventive strategies for MBD should target nutritional enhancement in combination with enhanced physical activity. MBD usually results in preventable morbidity in preterm and VLBW neonates. Treatment consists of optimum nutritional supplementation and enhanced physical activity.
\end{abstract}

Keywords: Extremely premature, hypocalcemia, hypophosphatemia, neonate, osteopenia, premature, rickets, very low birth weight

\section{Introduction}

Metabolic bone disease (MBD) in neonates is associated with reduced bone mineral content (BMC) leading to impaired skeletal mineralization. It is also known as osteopenia of prematurity and is a common consequence of numerous nutritional and biomechanical factors in premature neonates. BMC is inversely proportional to gestational age and birth weight and is influenced by the adequacy of calcium and phosphorus intake in postnatal life $(1,2)$. MBD may or may not be accompanied by rachitic changes $(3,4)$. Although advanced neonatal intensive care has led to improved survival of extremely preterm infants, this has not resulted in the abolition of morbidity and achieval of optimum growth $(5,6,7)$.

MBD is defined as decreased bone mineralization in neonates when compared to in utero or ex utero bone mineral density of neonates with equivalent gestational age or birth weight along with biochemical evidence and or radiological findings $(8,9)$.

\section{Magnitude of the Problem}

It has been reported that $55 \%$ of infants with extremely low birth weight (ELBW) (ELBW $\leq 1000$ grams birth weight) and $23 \%$ of infants with very LBW (VLBW) (VLBW $<1500$ and $>1000$ grams) have MBD. Similarly, it is more frequent in neonates under 28 weeks of gestation $(10,11)$. The incidence of MBD in breastfed, premature infants is $40 \%$ and in formula-fed, preterm infants (with oral calcium and phosphorus supplements) is $16 \%$. As the proportion of extremely preterm and ELBW neonates is increasing, the incidence of MBD is on the rise. Osteopenia occurs in about $50 \%$ of VLBW neonates and the majority of ELBW infants at 
40 weeks of post conceptional age, without adequate calcium and phosphorous supplementation $(10,11,12,13,14,15)$. It could be more prevalent in both developing and developed countries as more and more sick preterm neonates are being catered with enhanced survival $(5,14,15)$.

\section{Etiology}

MBD is often multifactorial (see Table 1). The leading causes are inadequate mineralization and include intrauterine growth restriction, prolonged parenteral nutrition (PN) (without phosphate) and delayed enteral nutrition. Neonates with insufficient calcium, phosphorous and vitamin D intake are at further risk of MBD when subjected to extended periods of immobilization $(3,4,5,6,7,8,9,10,11,12)$. The onset of MBD ensues between the $6^{\text {th }}$ and $16^{\text {th }}$ week of life or by 40 weeks of corrected age, although it may go unnoticed until marked demineralization takes place (loss of $20-40 \%$ of $\mathrm{BMC}$ ). The physiological basis of MBD is inadequate calcium and phosphorus stores in the face of accelerated fetal growth during the third trimester. In utero calcium and phosphorus accretion occurs at the rate of 120 $\mathrm{mg} / \mathrm{kg} /$ day and $60 \mathrm{mg} / \mathrm{kg} /$ day, respectively $(15,16)$. However, impaired supplementation and absorption of these minerals in post natal life leads to a sub-optimally mineralized new and remodelled skeletal system. Preterm, human milk has insufficient calcium, phosphorous and vitamin $\mathrm{D}$ per se,

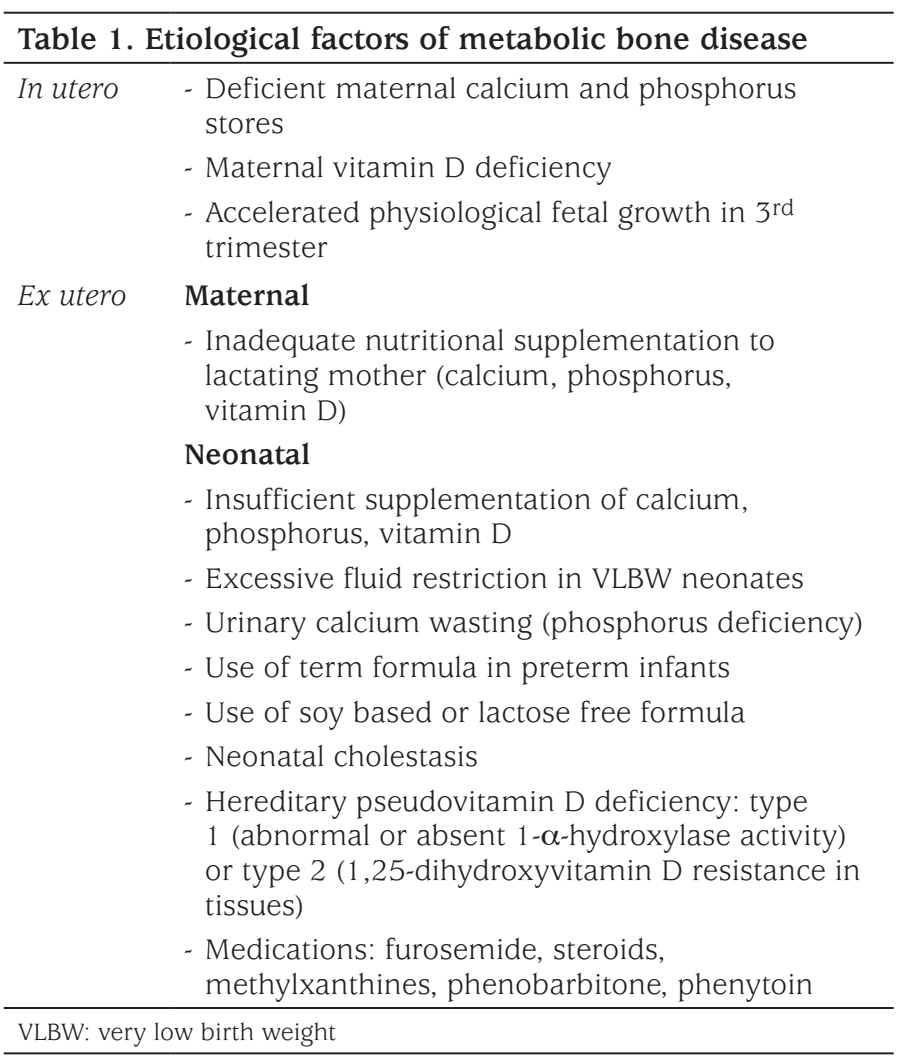

necessitating supplementation. Vitamin D concentration in human milk is 25 to $50 \mathrm{IU} / \mathrm{L}$ which is grossly insufficient to maintain serum 25-hydroxyvitamin D [25(OH)D] levels greater than $20 \mathrm{ng} / \mathrm{mL}$ in premature infants. This vitamin $\mathrm{D}$ deficiency leads to hypocalcemia, secondary hyperparathyroidism which in turn leads to phosphaturia. In addition, undue fluid restriction, use of term formula, and soy-based and lactose-free formulas in preterm neonates can contribute to MBD $(17,18,19,20,21)$. However, VLBW neonates can produce adequate 1,25-dihydroxyvitamin D levels after the initial few weeks of life if they have optimum dietary vitamin D supplementation. Some medications used in preterm infants including frusemide, steroids and methyl xanthines, which enhance osteoclastic activity, decrease osteoblastic proliferation, reduce calcium absorption and promote renal calcium wasting may lead to osteopenia (19,20,21). Similarly, extended administration of phenobarbital or phenytoin in neonates with seizures can lead to enhanced 25(OH)D metabolism and osteopenia (21).

Maternal vitamin D deficiency often occurs when lactating mothers have inadequate vitamin D (less than $600 \mathrm{IU} /$ day) supplementation. This often manifests as neonatal hypocalcemia and can result in congenital rickets. Neonates with cholestatic liver disease may have exaggerated malabsorption and impaired $25(\mathrm{OH}) \mathrm{D}$, which further aggravates osteopenia. Rare causes of hypovitaminosis D, such as hereditary pseudovitamin D deficiency type 1, due to abnormal or absent 1- $\alpha$-hydroxylase activity or type 2 due to 1,25-dihydroxyvitamin $\mathrm{D}$ resistance in tissues, can also lead to MBD (21). Chronic renal failure can also result in renal osteodystrophy and osteopenia.

Maintaining calcium and phosphorus levels in $\mathrm{PN}$ is difficult due to restricted solubility and temperature lability. Aminoacid, glucose, lipid concentration, $\mathrm{pH}$ and methods of preparation of calcium salts determine the bioavailability of calcium and phosphorus. Lowering the $\mathrm{pH}$ with cysteine enhances solubility.

\section{Pathophysiology}

\section{Calcium and Phosphorus Homeostasis}

The structural matrix of the skeletal system largely made up of calcium, phosphorus and magnesium and their homeostasis play a key role in bone integrity. The majority of total body calcium (99\%) and phosphorus (80\%) are present in bone as microcrystalline hydroxyapatite. The remainder of total body calcium (1\%) lies within the extracellular fluids and soft tissues. However, only $50 \%$ of total serum calcium is biologically active as being in the 
ionized form. The remaining calcium is bound to proteins (albumin and globulin: $40 \%$ ) and the rest (10\%) to organic and inorganic acids. Similarly, a major proportion of magnesium (60\%) is present in the bone matrix. Numerous factors such as vitamin D, parathyroid hormone (PTH), and calcitonin, followed by dietary calcium and phosphorous content, intestinal absorption, bone accretion, resorption and, finally, rate of urinary excretion determine calcium and phosphorus homeostasis (15).

\section{Role of PTH}

Soon after the birth, irrespective of gestational age and persisting mineral requirement, there is a fall in calcium, with a nadir attained at 24-30 hours after birth in preterm infants. As a result, there is a PTH surge. PTH augments calcium reabsorption in the kidney and also results in urinary phosphate wasting. PTH aids in the production of calcitriol $\left[1,25(\mathrm{OH})_{2} \mathrm{D}\right]$ by activating renal $25(\mathrm{OH}) \mathrm{D}_{3}-1$ alpha-hydroxylase, which increases intestinal calcium and phosphate absorption. PTH also promotes bone resorption and subsequent release of calcium and phosphate. On the whole, PTH has the greatest action in the kidney for regulating calcium metabolism. When there is insufficient calcium intake for prolonged periods, as with MBD, these metabolic changes persist (5).

\section{Fetal Bone Homeostasis}

The amount of minerals required for proper accretion of the skeleton vary according to the age of the baby. The fetus has a higher rate of skeletal growth, especially during the last trimester. There is an enormous increase in bone volume with advanced gestational age due to bone remodelling and augmented bone synthesis as seen by increased trabecular thickness. It has been shown that the rate of trabecular thickening is 240 times more rapid in the fetus compared to children (15). Fundamentally, osteoblasts produce osteoid/ organic bone matrix into which calcium and phosphate hydroxyapatite are incorporated. This osteoblastic activity increases exponentially, involving $80 \%$ of mineral accretion, during the period of 24 to 37 weeks of gestation $(22,23,24,25,26)$.

Normally the fetal nutrient supply of protein, energy and minerals is ample for fetal growth and skeletal development $(1.2 \mathrm{~cm} /$ week). The physical density of bone (expressed as bone mass divided by bone volume) is highest in term neonates. The calcium and phosphate deposition during the last trimester of fetal life is around 20 grams and 10 grams respectively, which corresponds to a calcium and phosphate accretion rate of $100-120 \mathrm{mg} / \mathrm{kg} /$ day and $50-65 \mathrm{mg} / \mathrm{kg} / \mathrm{day}$ respectively $(15,16)$.
The placenta has a pivotal role in fetal skeletal development as calcium is actively transported transplacentally with the aid of a calcium pump in the basement membrane $(22,23,24,25,26)$ with a maternal to fetal calcium gradient of $1: 4$. In addition, activation of vitamin $D$ to 1,25-dihydroxy cholecalciferol also occurs in the placenta, which is an essential element of transplacental phosphate transfer (26). Thus, there is a hypercalcemic status in fetal life due to increased estrogen levels, resulting in enhanced bone modelling and endocortical bone formation (27). All these processes are interupted in preterm neonates, predisposing them to under mineralization of the bone. In addition chronic placental inflammation (chorioamnionitis), or placental insufficiency, as indicated by intrauterine growth retardation, impairs transplacental transfer of calcium and phosphorous creating an osteopenic milieu in the fetus. As placental calcium levels and fetal bone accretion depend on maternal dietary calcium intake, calcium supplementation of 2 grams on or after 22 weeks of gestation to pregnant women enhances neonatal BMC $(15,26)$.

\section{Neonatal Bone Homeostasis}

It has been noted that from birth to six months of age, bone physical density is reduced by one third in term neonates $(15,27)$. This results is because of the preferential rapid widening of the bone marrow cavity compared to the cortical surface area. However, term neonates generally maintain bone integrity, unlike preterm infants. There is a fall in transplacentally transferred estrogens and serum calcium levels after birth leading to a rise in PTH $(28,29)$. However, within the first 48 hours of life, falling serum calcium levels do not result in a corresponding rise in serum PTH levels which in turn leads to a nadir in serum calcium levels. It is notable that serum PTH concentrations in term neonates remain within the optimum range for term neonates or adults; they show a falling trend from foetal levels based on measurement in large cohorts of foetuses and neonates not necessarily measured in the same neonates at different points of time $(5,15,17)$.

Calcium absorption in post natal life is a function of type and amount of calcium intake, gastrointestinal function, including both active and passive transport of calcium, and vitamin D levels in the mother. Preterm neonates with reduced intake and inefficient absorption of calcium and phosphorous from the gut are at a twofold disadvantage and are prone to MBD. Oral calcium bioavailability is compromised in cases of large gastric aspirates, vomiting, abdominal distension and constipation, which are often seen in preterm neonates. The interplay of calcium and phosphorous absorption is such that when the dietary levels 
are disproportionate, one reduces the other's absorption. Apart from nutritional supplementation, another important factor regulating osteoblastic activity is physical activity during fetal life such as quickening against the uterine wall, which may be lost in sick, preterm neonates who are less active in post natal life. Reduced physical activity enhances osteoclastic activity and inhibits osteoblastic activity, leading to bone resorption and urinary calcium wasting $(30,31,32,33)$.

Interestingly, the in utero rise in bone mineral apparent density (BMAD) is faster than that found in ex utero babies. $B M A D$ is measured by dividing $B M C$ with the surface area of bone $\left(\mathrm{BMC} / \mathrm{BA}=\mathrm{g} / \mathrm{cm}^{3}\right)$ and is a measure of volumetric BMD. It initially falls after birth but is maintained later on (33). Preterm neonates will have a fall in mineral accretion when compared to fetal life, although skeletal growth remains comparable, and thus leads to osteopenia of prematurity. However, after adequate nutritional supplementation, catch up bone growth begins in preterm VLBW infants.

\section{Clinical Features and Signs}

The clinical manifestations are diverse depending up on the degree of demineralization. MBD can either remain unnoticeable or can present with florid rickets. It can also present as arrested growth velocity and with features of hypocalcemia such as jitteriness or tetany. Affected neonates may have a large head, craniotabes, frontal bossing, sutural separation in the skull, wide fontanelle, costochondral thickening, hypotonia, and protruding abdomen, although this is not consistently present. MBD may manifest with multiple pathological or spontaneous fractures of the ribs and long bones, which is seen in $10 \%$ of premature neonates and these present as pain while handling (see Table 2) (3). Rib softening and/or fractures may lead to deranged pulmonary function and respiratory distress around 5 to 11 weeks of age $(34,35)$. These infants can have prolonged ventilator requirement or difficulty in weaning from the ventilator.

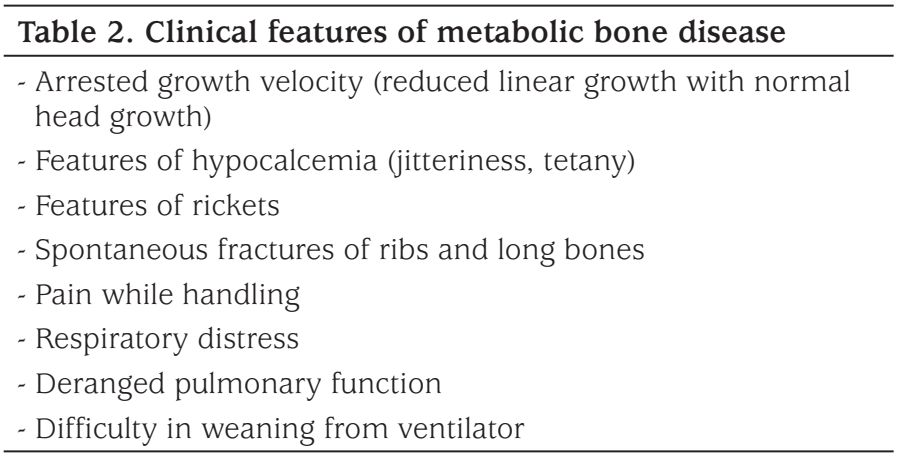

\section{Diagnosis}

\section{Biochemistry}

The mainstay of diagnosis is by estimation of biochemical markers which should include serum calcium, phosphorous, PTH and alkaline phosphatase (ALP) and urinary calcium concentrations (see Table 3). The predominant biochemical change includes decreased serum phosphorus levels. Hypophosphatemia is an early indicator of disrupted calcium metabolism and manifests by 7-14 days of life. This can occur either due to isolated phosphate deficiency or to elevated PTH levels. Phosphate depletion increases calcitriol synthesis and may lead to hypercalcemia which supresses PTH levels. In addition phosphate reabsorption is increased by the kidney and thus tubular reabsorption of phosphate is also a useful measure of phosphate homeostasis.

Serum ALP levels $\geq 900$ IU/L show $100 \%$ sensitivity and $70 \%$ specificity for MBD and ALP concentrations may increase fivefold in MBD (35). Caution should be exercised in interpretation of elevated ALP levels as these may be a symptom of hepatic and/or gastrointestinal diseases because this enzyme is also produced by the liver and gastrointestinal tract. Hence, estimation of the bone isoenzymeof ALP is more specific for a skeletal cause and thus to diagnose MBD $(36,37,38)$. PTH levels have better specificity than ALP in diagnosing MBD. PTH levels $>180 \mathrm{pg} /$ $\mathrm{mL}$ or phosphate concentration $<4.6 \mathrm{mg} / \mathrm{dL}$ at three weeks after delivery have $100 \%$ sensitivity and $94 \%$ specificity for the diagnosis of severe MBD $(6,15,17,36,37,38)$. Ryan et al

\footnotetext{
Table 3. Diagnosis of metabolic bone disease

Biochemical

- Decreased serum phosphorus levels [ $<3.5$ to $4 \mathrm{mg} / \mathrm{dL}$ (1.1 to $1.3 \mathrm{mmol} / \mathrm{L})]$,

- Increased serum alkaline phosphatase levels

- Elevated bone isoenzymes of alkaline phosphatase

- Low or normal serum calcium levels

- Low or normal serum 25(OH)D levels

- Elevated serum PTH levels (often variable)

- Low urinary calcium and phosphorus levels

Radiological

- Radiograph of long bone: widening of epiphyseal growth plates; metaphysis rarefaction, cupping, fraying, subperiosteal new bone formation and osteopenia

- Radiograph of the skull, spine, scapula. Demonstration of osteopenia

- Radiograph of the chest: osteopenia and rachitic changes, pathologic fractures in ribs

- DEXA: reduced bone mineral content

- Quantitative ultrasound: reduced bone SOS

25(OH)D: 25-hydroxyvitamin D, PTH: parathyroid hormone, DEXA: dual

energy X-ray absorptiometry, SOS: speed of sound
} 
(37) in a cohort of 108 preterm neonates, failed to find any association between serum ALP levels and BMC when they reached term.

These biomarkers should be estimated at initial diagnosis and later, during follow-up at four-weekly intervals, to monitor the response to treatment (Figure 1). The fundamental principle in treating these neonates is to establish normocalcemia, normophosphatemia and to prevent urinary calcium wasting. With the normalization of calcium, phosphorus and ALP, evaluation of these parameters should be performed every month up to six months of age and can be done once every three months, thereafter.

\section{Imaging}

Various imaging modalities have been used to diagnose MBD (see Table 3). Plain X-rays will show osteopenia, reduced cortical thickness, rib fractures, widening of the epiphysis, and uneven margins (39). Dual energy X-ray absorptiometry (DEXA) is an imaging tool to detect even small changes in BMC and BMD and to predict the probability of impending fractures. DEXA has been standardized in both term and preterm neonates. Although DEXA has diagnostic precision for bone mineralization, it involves exposure to ionizing radiation and cannot be performed at the bedside $(40,41)$.

Another newer, non-invasive diagnostic modality for MBD is measuring bone speed of sound (SOS) by quantitative ultrasound. This method does not expose to radiation, can be done bedside and has reference standards for both term and preterm infants, both at birth and during follow up. SOS by quantitative ultrasound measures bone density, delineates the structure and enables prediction of bone turnover in preterm infants. This is usually performed using the mid-tibial shaft. Bone SOS is increased in term infants (median $3079 \mathrm{~m} / \mathrm{s}$ ) compared with preterm infants (median $2911 \mathrm{~m} / \mathrm{s}$ ). Similarly, there is a good correlation between gestational age and bone SOS. Also, bone SOS was noted to be low in preterm infants even at a corrected age of 40 weeks when compared with term infants $(42,43,44,45)$.

\section{Management}

The principles of management of MBD in preterm neonates are multidimensional (see Figure 2, Table 4) (29).

\section{Mineral Requirements of Infants}

The requirements of calcium and phosphorus are based on intrauterine bone mineral accretion rates. The ideal calcium to phosphorus ratio for optimum skeletal mineralization is 1.7:1 (46). While on PN, use of soluble forms of calcium and phosphorus such as sodium and potassium phosphate, glycerol phosphate or sodium-glucose phosphate, will improve bioavailability $(15,21)$.

Vitamin $\mathrm{D}$ requirement is a function of gestational age and maternal vitamin D levels. The fetus is capable of metabolizing vitamin D to 1,25-dihydroxyvitamin D from

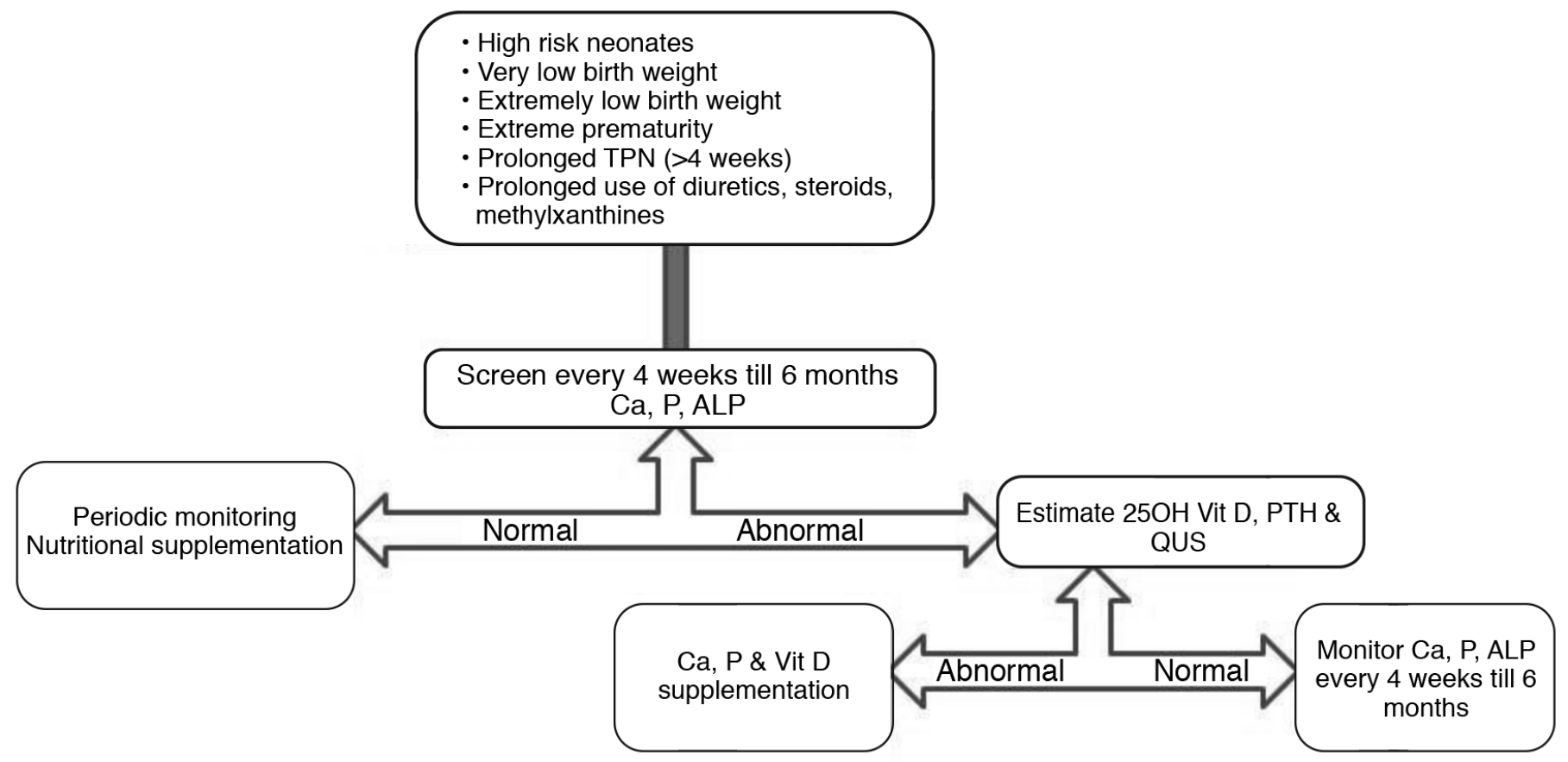

Figure 1. Algorithm for screening of metabolic bone disease

ALP: alkaline phosphatase, PTH: parathyroid hormone, TPN: total parenteral nutrition 
the $24^{\text {th }}$ week of gestation. It is recommended to provide 400 IU of vitamin D daily for all premature neonates after establishment of full feeds (21).

Calcium and phosphorus requirements in preterm neonates are 123 to $185 \mathrm{mg} \mathrm{Ca} / 100 \mathrm{kcal}$ and 80 to $110 \mathrm{mg} \mathrm{P} / 100$ kcal, respectively. This can be achieved with fortification of human milk and with formula milk. Calcium is in the form of soluble calcium glycerol phosphate in formula milk achieving $90 \mathrm{mg} / \mathrm{kg} /$ day of calcium absorption (88\% of the total). Thus, fortification and supplementation is often mandatory in preterm neonates.

The effects of human milk fortifiers on skeletal mineralization are inconclusive as reported in the Cochrane systematic

\begin{tabular}{|c|c|}
\hline \multicolumn{2}{|c|}{ Short term TPN (first 1-2 weeks) } \\
\hline Calcium & 40-120 mg/kg/day \\
\hline Phosphate & $31-71 \mathrm{mg} / \mathrm{kg} / \mathrm{day}$ \\
\hline Vitamin D & 160-280 IU/day \\
\hline \multicolumn{2}{|c|}{ Prolonged TPN (3-4 weeks) } \\
\hline Calcium & $75-90$ mg/kg/day \\
\hline Phosphate & $60-70 \mathrm{mg} / \mathrm{kg} / \mathrm{day}$ \\
\hline Vitamin D & 160-280 IU/day \\
\hline \multicolumn{2}{|c|}{ Full enteral feeding } \\
\hline Calcium & $140-160 \mathrm{mg} / \mathrm{kg} / \mathrm{day}$ \\
\hline Phosphate & $95-108 \mathrm{mg} / \mathrm{kg} / \mathrm{day}$ \\
\hline Vitamin D & 200-400 IU/day \\
\hline
\end{tabular}

Figure 2. Mineral requrements during total parenteral nutrition and enteral feeds The American Academy of Pediatrics

Ref. 29,65,66

TPN: total parenteral nutrition

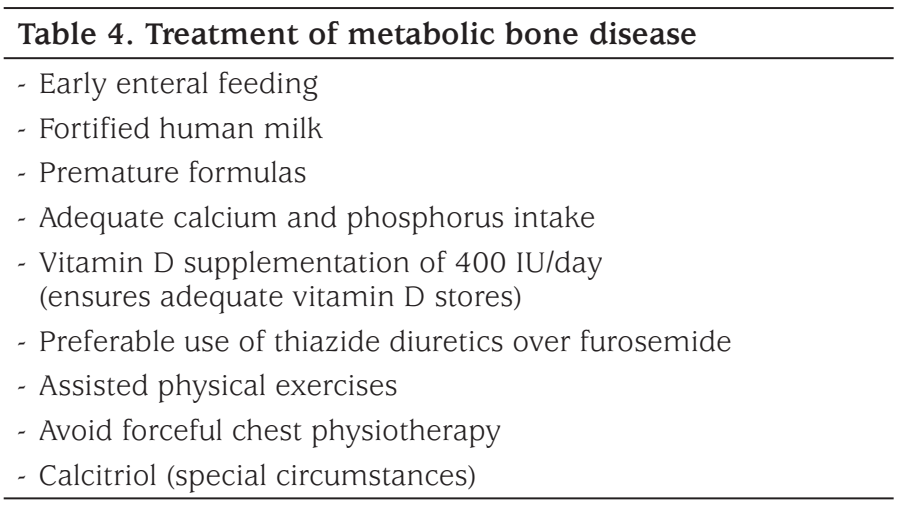

review and meta analysis of Kuschel and Harding (46). Use of milk fortifiers may predispose to necrotizing enterocolitis with higher doses of calcium, due to increased gastrointestinal transit time, fecal calcium and reduced absorption of fat.

\section{Prognosis and Outcome}

As MBD resolves spontaneously with adequate calcium, phosphorous and vitamin D supplementation, it carries a good prognosis. Although there are differences of opinions about duration, amount and route of mineral supplementation, it has been reported that infants receiving formula feeds until nine months of age have higher BMC $(6,15)$. Also, it has been stated that preterm infants have an adequate catch up by one year of life with optimum supplementation as demonstrated by quantitative ultrasound and DEXA measurements $(21,33,39)$. Skeletal mineralization of term and preterm infants is comparable in later childhood. Similarly, studies have shown reduced spinal BMC in later childhood in LBW neonates who are stunted $(3,5,6,15)$.

Assisted physical exercise is a newer preventive modality which adds to nutritional management in stable premature neonates. Chen et al (43) found that early assisted exercise in VLBW neonates enhanced bone strength. The assisted physical exercise gives either tactile stimulation with moderate pressure strokes or kinaesthetic stimulation with passive flexion and extension of both upper limbs and lower limbs. It was shown to enhance body weight, bone mineralization and osteogenesis. Some studies have shown that exercise may attenuate postnatal reduction in bone $\operatorname{SOS}(47,48,49,50,51)$.

It is interesting that nutrition plays a dual role in MBD, both therapeutic and preventive $(52,53,54,55,56,57,58)$. Supplementing mothers with 600 IU/day of vitamin D univerasally has also been shown to help in preventing MBD (59). Focusing on the optimum supply of minerals and of vitamin D, by using human milk fortifier, calcium and phosphorous supplementation or preterm formula is vital to prevent MBD $(60,61,62,63,64,65,66)$.

\section{Conclusion}

Optimum nutritional supplementation of neonates with calcium, phosphorus, and vitamin D, along with assisted physical exercise has been shown to be effective in preventing much MBD. These measures inhibit pathological bone resorption in the initial few weeks of life and enhance the growth of premature infants. It is also vital to identify the biochemical abnormalities characteristic of MBD in a timely manner to 
initiate therapeutic interventions at the earliest opportunity and thus prevent spontaneous/pathological fractures. Periodic estimation of phosphate and alkaline phosphatase concentrations is important to estimate the risk of osteopenia, along with assessment of treatment efficacy. Similarly, DEXA and quantitative ultrasound enable quantification of bone mineralization and assist in nutritional rehabilitation. Additionally, maternal vitamin D supplementation is another essential preventive strategy for MBD.

\section{Ethics}

Peer-review: Externally and internally peer-reviewed.

\section{Authorship Contributions}

Surgical and Medical Practices: Swathi Chacham, Rachna Pasi, Najeeb Ahmad, Concept: Swathi Chacham, Rachna Pasi, Madhuradhar Chegondi, Najeeb Ahmad, Design: Swathi Chacham, Rachna Pasi, Madhuradhar Chegondi, Najeeb Ahmad, Data Collection or Processing: Najeeb Ahmad, Shanti Bhusan Mohanty, Analysis or Interpretation: Swathi Chacham, Rachna Pasi, Madhuradhar Chegondi, Najeeb Ahmad, Shanti Bhusan Mohanty, Literature Search: Swathi Chacham, Rachna Pasi, Madhuradhar Chegondi, Najeeb Ahmad, Shanti Bhusan Mohanty, Writing: Swathi Chacham, Rachna Pasi, Madhuradhar Chegondi, Najeeb Ahmad, Shanti Bhusan Mohanty.

Financial Disclosure: The authors declared that this study received no financial support.

\section{References}

1. Demarini S. Calcium and phosphorus nutrition in preterm infants. Acta Paediatr Suppl 2005;94:87-92.

2. Takada M, Shimada M, Hosono S, Tauchi M, Minato M, Takahashi S, Okuni M, Takeuchi S. Trace elements and mineral requirements for very low birth weight infants in rickets of prematurity. Early Hum Dev 1992;29:333-338.

3. Koo WW, Sherman R, Succop P, Krug-Wispe S, Tsang RC, Steichen JJ, Crawford AH, Oestreich AE. Fractures and rickets in very low birth weight infants: conservative management and outcome. J Pediatr Orthop 1989;9:326-330.

4. Chacham S, Pasi R. Assisted Physical Exercise for Preterm Neonates. Indian Pediatr 2018;55:111-112.

5. Rustico SE, Calabria AC, Garber SJ. Metabolic bone disease of prematurity. J Clin Transl Endocrinol 2014;1:85-91.

6. Backstrom MC, Kuusela AL, Maki R. Metabolic bone disease of prematurity. Ann Med 1996;28:275-282.

7. Steichen J, Gratton TL, Tsang RC. Osteopenia of prematurity: The cause and possible treatment. J Pediatr 1980;96:528-534.

8. Forbes GB. Calcium accumulated by the human fetus. Pediatrics 1976;57:976-977.

9. Ziegler EE, O’Donnell AM, Nelson SE, Fomon SJ. Body composition of the reference fetus. Growth 1976;40:329-341
10. Callenbach JC, Sheehan MB, Abramson SJ, Hall RT. Etiologic factors in rickets of very low birth-weight infants. J Pediatr 1981;98:800-805.

11. James JR, Condon PJ, Truscott J, Horsman A, Arthur R. Osteopenia of prematurity. Arch Dis Child 1986;61:871-876.

12. Mazess RB, Whedon GD. Immobilization and bone. Calcif Tissue Int 1983;35:265-267

13. Agarwal R, Deorari A, Paul VK. AIIMS Protocols in Neonatology. New Delhi, CBS Publishers \& Distributors Pvt Ltd, 2015.

14. Natarajan CK, Sankar MJ, Agarwal R, Pratap OT, Jain V, Gupta N, Gupta AK, Deorari AK, Paul VK, Sreenivas V. Trial of daily vitamin D supplementation in preterm infants. Pediatrics 2014;133:e628-e634.

15. Bozzetti V, Tagliabue P. Metabolic Bone Disease in preterm newborn: an update on nutritional issues. Italian J of Pediatr 2009;35:20.

16. Sparks JW. Human intrauterine growth and nutrient accretion. Semin Perinatol 1984;8:74-93

17. Hsu HC, Levine MA. Perinatal calcium metabolism: physiology and pathophysiology. Semin Neonatol 2004;9:23-36.

18. Abrams SA, Hawthorne KM, Placencia JL, Dinh KL. Micronutrient requirements of high-risk infants. Clin Perinatol 2014;41:347-361.

19. Mitchell SM, Rogers SP, Hicks PD, Hawthorne KM, Parker BR, Abrams SA. High frequencies of elevated alkaline phosphatase activity and rickets exist in extremely low birth weight infants despite current nutritional support. BMC Pediatr 2009;9:47.

20. Mimouni FB, Mandel D, Lubetzky R, Senterre T. Calcium, phosphorus, magnesium and vitamin $\mathrm{D}$ requirements of the preterm infant. World Rev Nutr Diet 2014;110:140-151

21. Abrams SA. Osteopenia (Metabolic Bone Disease) of Prematurity. In: Eichenwald EC, Hansen AR, Martin C, Stark AR (eds). Cloherty and stark's manual of neonatal care. 8th ed. Philadelphia: Wolters Kluwer, 2017;853-857

22. Kovacs CS, Kronenberg HM. Maternal-fetal calcium and bone metabolism during pregnancy, puerperium and lactation. Endocr Rev 1997; 18:832-872.

23. Care AD. The placental transfer of calcium. J Dev Physiol 1991;15:253257.

24. Weisman Y, Harell A, Edelstein S, David M, Spirer Z, Golander A. 1 alpha, 25-Dihydroxyvitamin D3 and 24,25- Dihydroxyvitamin D3 in vitro synthesis by human deciduas and placenta. Nature 1979;281:317-319.

25. Rigo J, Senterre J. Nutritional needs of premature infants: current issues. J Pediatric 2006;149:S80-S88.

26. Ryan S, Congdon PJ, James J, Truscott J, Horsman A. Mineral accretion in human fetus. Arch Dis Child 1988;63:799-808.

27. Koo WW, Walters JC, Esterlitz J, Levine RJ, Bush AJ, Sibai B. Maternal calcium supplementation and fetal bone mineralization. Obstet Gynecol 1999;94:577-582.

28. Toth P, Erdei G, Vasarhelyi B. Potential consequences of the sudden postnatal drop of estrogens level in preterm neonates. Orv Hetil 2003;144:1719-1724

29. Abrams SA. Committee on Nutrition. Calcium and vitamin $\mathrm{D}$ requirements of enterally fed preterm infants. Pediatrics 2013;131:e1676-e1683.

30. Miller ME. Hypothesis: fetal movement influences fetal and infant bone strength. Med Hypotheses 2005;65:880-886.

31. Miller ME. The bone disease of preterm birth: a biomechanical perspective. Pediatr Res 2003;53:10-15.

32. Rauch F, Schoneau E. Skeletal development in premature infants a review of bone physiology beyond nutritional aspects. Arch Dis Child Fetal Neonatal 2002;86:F82-F85 
33. Specker BL, Mulligan L, Ho M. Longitudinal study of calcium intake, physical activity and bone mineral content in infants 6-18 months of age. J Bone Miner Res 1999;14:569-576.

34. Glasgow JS, Thomas PS. Rachitic respiratory distress in small preterm infants. Arch Dis Child 1977;52:268-273.

35. Bishop N. Bone disease in preterm infants. Arch Dis Child 1989;64:14031409.

36. Backstrom MC, Kouri T, Kuusela AL, Sievanen H, Kiovisto AM, Ikonen RS, Mäki M. Bone isoenzyme of serum alkaline phos-phatase and serum inorganic phosphate in metabolic bone disease of prematurity. Acta Paediatr 2000;89:867-873.

37. Ryan SW, Truscott J, Simpson M, James J. Phosphate, alkaline phosphatase and bone mineralization in preterm neonates. Acta Paediatr 1993;82:518-521.

38. Faerk J, Peitersen B, Petersen S, Michaelsen KF. Bone mineralisa-tion in premature infants can be predicted from serum alkaline phopshatase or serum phosphate. Arch Dis Child Fetal Neonatal 2002;87:F133-F136.

39. Ardran GM. Bone destruction not demonstrable by radiography. Br J Radiol 1951;24:107-109.

40. Rigo J, Nyamugabo K, Picaud JC, Gerard P, Pieltain Catherine, de Curtis Mario. Reference values of body com-position obtained by DEXA in preterm and term neonates. J Pediatr Gastroenterol Nutr 1998;27:184190.

41. Bruton JA, Bayleys HS, Atkinson SA. Validation and application of dual-energy X-ray absorpiometry tto measure bone mass and body composition in small infants. Am J Clin Nutr 1993;58:839-845.

42. Shaw SC, Sankar MJ, Thukral A, Natarajan CK, Deorari AK, Paul VK, Agarwal R. Assisted physical exercise for improving bone strength in preterm infants less than 35 weeks gestation: A randomized controlled trial. Indian Pediatr 2018;55:115-120.

43. Chen HL, Lee CL, Tseng HI, Yang SN, Yang RC, Jao HC. Assisted exercise improves bone strength in very low birth weight infants by bone quantitative ultrasound. J Pediatr Child Health 2010;46:653-659.

44. Nemet D, Dolfin T, Wolach B, Eliakim A. Quantitative ultrasound measurements of bone speed of sound in premature infants. Eur J Pediatr 2001;160:736-740.

45. McDevitt H, Tomlinson C, White MP, Ahmed SF. Quantitative ultrasound assessment of bone in preterm and term neonates. Arch Dis Child Fetal Neonatal Ed 2005;90:F341-F342.

46. Kuschel CA, Harding JE. Multicomponent fortified human milk for promoting growth in preterm infants. Cochrane Database Syst Rev 2004:CD000343.

47. Schulzke SM, Kaempfen S, Trachsel D, Patole SK. Physical activity programs for promoting bone mineralization and growth in preterm infants. Cochrane Database Syst Rev 2014:CD005387.

48. Eliakim A, Litmanovitz I, Nemet D. The role of exercise in prevention and treatment of osteopenia of prematurity: An Update. Pediatr Exerc Sci 2017;29:450-455.

49. Field T, Diego M, Hernandez-Reif M. Preterm infant massage therapy research: A review. Infant Behav Dev 2010;33:115-124.

50. Erdem E, Tosun O, Bayat M, Korkmaz Z, Halis H, Gunes T. Daily physical activity in low-risk extremely low birth weight preterm infants: positive impact on bone mineral density and anthropometric measurements. J Bone Miner Metab 2015;33:329-334.
51. Moyer-Mileur LJ, Ball SD, Brunstetter VL, Chan GM. Maternal administered physical activity enhances bone mineral acquisition in premature very low birth weight infants. J Perinatol 2008;28:432-437.

52. Munns CF, Shaw N, Keily M, Specker BL, Thacher TD, Ozono K, Michigami T, Tiosano D, Mughal MZ, Mäkitie O, Ramos-Abad L, Ward L, DiMeglio LA, Atapattu N, Cassinelli H, Braegger C, Pettifor JM, Seth A, Idris HW, Bhatia V, Fu J, Goldberg G, Sävendahl L, Khadgawat R, Pludowski P, Maddock J, Hyppönen E, Oduwole A, Frew E, Aguiar M, Tulchinsky T, Butler G, Högler W. Global Consensus Recommendations on Prevention and Management of Nutritional Rickets. J Clin Endocrinol Metab 2016;101:394-415.

53. Garcia AH, Erler NS, Jaddoe VW, Tiemeier H, van den Hooven EH, Franco OH, Rivadeneira F, Voortman T. 25-hydroxyvitamin D concentrations during fetal life and bone health in children aged 6 years: a population-based prospective cohort study. Lancet Diabetes Endocrinol 2017;5:367-376.

54. Khadilkar A, Khadilkar V, Chinnappa J, Rathi N, Khadgawat R, Balasubramanian S, Parekh B, Jog P. Prevention and treatment of vitamin $\mathrm{D}$ and calcium deficiency in children and adolescents: Indian Academy of Pediatrics (IAP) guidelines. Indian Pediatr 2017;54:567573.

55. Mandlik R, Kajale N, Ekbote V, Patwardhan V, Khadilkar V, Chiplonkar $\mathrm{S}$, Khadilkar A. Determinants of Vitamin D status in Indian schoolchildren. Indian J Endocr Metab 2018;22:244-248.

56. Ritu G, Gupta A. Vitamin D deficiency in India: Prevalence, causalities and interventions. Nutrients 2014;6:729-775.

57. Simmonds CS, Kovacs CS. Role of parathyroid hormone (PTH) and $\mathrm{PTH}$-related protein (PTHrP) in regulating mineral homeostasis during fetal development. Crit Rev Eukaryot Gene Expr 2010;20:235-273.

58. Ukarapong S, Venkatarayappa SKB, Navarrete C, Berkovitz G. Risk factors of metabolic bone of prematurity. Early Hum Dev 2017;112:2934.

59. Von Websky K, Hasan AA, Reichetzeder C, Tsuprykov O, Hocher B. Impact of vitamin $\mathrm{D}$ on pregnancy-related disorders and on offspring outcome. J Steroid Biochem Mol Biol 2018;180:51-64.

60. Christmann V, Gradussen CJ, Körnmann MN, Roeleveld N, van Goudoever JB, van Heijst AF. Changes in biochemical parameters of the calciumphosphorus homeostasis in relation to nutritional intake in very-low-birthweight infants. Nutrients 2016;8:764.

61. Chin LK, Doan J, Teoh YS, Stewart A, Forrest P, Simm PJ. Outcomes of standardised approach to metabolic bone disease of prematurity. J Padiatr Child Health 2017;54:665-670.

62. Stalnaker KA, Poskey GA. Osteopenia of prematurity: does physical activity improve bone mineralization in preterm infants? Neonatal Netw 2016;35:95-104.

63. Isojima T, Kushima R, Goishi K, Tsuchida S, Watanabe T, Takahashi N, Kitanaka S. Mineral status of premature infants in early life and linear growth at age 3. Pediatr Int 2015;57:864-869.

64. Lee SYR. Prevention of metabolic bone disease of prematurity by optimizing calcium and phosphate contents in parenteral nutrition for premature infants. J Hum Nutr Food Sci 2017;5:1106.

65. Harrison CM, Johnson K, McKechnie E. Osteopenia of prematurity: a national survey and review of practice. Acta Paediatr 2008;97:407-413.

66. Faienza MF, D’Amato E, Natale MP, Grano M, Chiarito M, Brunetti G, D’Amato G. Metabolic Bone Disease of Prematurity: Diagnosis and Management. Front Pediatr 2019;7:143. 